\title{
Isocromosoma 18q en mosaico: Caso clínico
}

\author{
MARÍA PAZ MUÑOZ F. $.^{1},{ }^{2}$ ISABEL AVENDAÑO B. ${ }^{1}$, \\ MARIANA ARACENA A. ${ }^{3}$, TM XIMENA GUERRERO C. ${ }^{3}$ \\ 1. Unidad de Pediatría Centro Referencia Salud Cordillera Oriente. \\ 2. Departamento de Pediatría y Cirugía Infantil Oriente, Universidad de Chile. \\ 3. Unidad de Genética Hospital Luís Calvo Mackenna.
}

\begin{abstract}
Mosaic Isochromosome 18q: case-report

Background: The Isochromosome $18 \mathrm{q}$ and chromosome 18 short arm deletion (18p-) constitute structural anomalies that are reported with certain frequency in the literature. However, the association of both abnormalities in a patient is very uncommon. Objective: Description of a clinical case of Isochromosome 18 with emphasys in the few phenotypic manifestations. Case-report: Female infant 18 months-old, with short stature, minor dysmorphic features and a slight psychomotor developmental delay, whose chromosomal study in peripheral blood showed a chromosomal mosaicism with two cell lines: chromosome 18 long arm isochromosome and deletion of chromosome 18 short arm. The chromosomal analysis of both parents did not show numerical neither morphological alterations. Discussion: This case illustrates the importance of requesting a karyotype in patients with small stature, dysmorphic features and/or malformations. The patient clinical features are compared with other similar cases described in the literature. The coexistence of both structural abnormalities (mosaicism) is extremely uncommon.

(Key words: Isochromome 18, small stature, chromosomal mosaicism, dysmorphic features).

Rev Chil Pediatr 2009; 80 (2): 157-160
\end{abstract}

\section{RESUMEN}

Introducción: El Isocromoma 18q y la deleción del brazo corto del cromosoma 18 (18p-), son anomalías estructurales que se reportan con cierta frecuencia en la literatura. Sin embargo, la asociación de ambas alteraciones en una misma paciente es muy infrecuente. Objetivo: Descripción de un caso clínico de Isocromosoma 18 con énfasis en la escasas manifestaciones fenotípicas. Caso Clínico: Lactante femenino de 18 meses de edad portador de talla baja, dismorfias menores y un leve retraso del desarrollo sicomotor, cuyo estudio cromosómico en sangre periférica mostró un mosaico compuesto por un isocromosoma del brazo largo del cromosoma 18 y otro cromosoma 18 con deleción del brazo p. El análisis cromosómico de ambos padres no mostró alteraciones numéricas ni morfológicas. Discusión: Este caso ilustra la importancia de solicitar un cariograma en pacientes con talla baja, dismorfias y/o malformaciones. Se describen las malformaciones encontradas y se compara con otros casos similares descritos en la literatura. La alteración estructural en mosaico reportada es sumamente infrecuente.

(Palabras clave: Isocromosoma 18q, talla baja, dismorfias, mosaicismo cromosómico).

Rev Chil Pediatr 2009; 80 (2): 157-160

Trabajo recibido el 22 de diciembre de 2008, devuelto para corregir el 12 de enero de 2009, segunda versión el 12 de febrero de 2009, aceptado para publicación el 16 de febrero de 2009.

Correspondencia a:

Dra. María Paz Muñoz F.

E-mail: pazmunioz@gmail.com 


\section{Introducción}

El Isocromoma 18q [i(18q)] y la deleción del brazo corto del cromosoma 18 (18p-), son anomalías estructurales que se reportan con cierta frecuencia en la literatura. Sin embargo, la coexistencia de ambas alteraciones en un mismo individuo es muy infrecuente $e^{1,2}$.

Un isocromosoma es un cromosoma en el que se ha perdido un brazo y el otro se ha duplicado de forma especular. El isocromosoma $18 \mathrm{q}$ es una condición infrecuente y la mayor parte de los casos son detectados prenatalmente o bien en lactantes menores por sus malformaciones cardíacas graves ${ }^{3,4}$. En esta alteración, consistente en dos brazos largos (q) de este cromosoma reunidos a nivel del centrómero, los afectados tienen algunos rasgos de trisomía 18, dada las tres copias de su brazo largo (trisomía 18q). Ellos presentan retraso desarrollo severo, cardiopatía congénita, fisura palatina y malformaciones de extremidades, todo lo cual compromete su sobrevida postnatal ${ }^{2,6}$.

Por el contrario, el fenotipo de la monosomía 18 p no es llamativo y se les describe con epicanto, puente nasal bajo, cuello corto, ancho y talla baja ${ }^{7,8}$. En algunos de ellos se observa malformaciones del SNC, con silla turca vacía ${ }^{9,10}$.

Se reporta el caso de una niña con un mosaicismo cromosómico, tiene dos complementos cromosómicos diferentes. En una línea celular se observa un isocromosoma del brazo largo del cromosoma 18 y en la otra una deleción del brazo corto del cromosoma 18 . Se enfatiza la escasez de manifestaciones clínicas.

\section{Caso clínico}

Paciente de sexo femenino que fue derivada desde atención primaria a control en el Centro de Referencia Salud Cordillera Oriente, a la edad de 1 año 5 meses por talla baja. Primera hija de padres jóvenes sanos, embarazo controlado que cursó con oligoamnios. Parto de término eutócico, Peso: 2730 gr, Talla: $48 \mathrm{~cm}$ y Circunferencia cráneo: $32,5 \mathrm{~cm}$. Apgar 9-9, no presenta patología neonatal.

Se pesquisa talla baja a los 6 meses de vida, edad a la que también consulta por constipación severa, encontrándose malformación rectal: fístula peri anal. Se realiza anorectoplastía sagital posterior a los 9 meses sin incidentes.

Al momento de la consulta no presenta síntomas digestivos ni intercurrencias.

Al examen físico (figura 1) destaca talla baja proporcionada, normocráneo, telecanto, puente nasal bajo, cuello corto, leve pterigion, tórax simétrico, auscultación cardiopulmonar normal, abdomen sin visceromegalias. Genitales femeninos normales. Extremidades hiperlaxas. Peso 9200 (P/E -1 DS), Talla $71 \mathrm{~cm}$ (T/E -2 DS) $\mathrm{P} / \mathrm{T}$ Normal.

Se solicita estudio: hemograma, función renal y hepática, gases venosos y electrolitos plasmáticos, glicemia y hormonas tiroideas normales; anticuerpos antigliadina y antiendomisio negativos, inmunoglobulina Ig A normal por rango edad, calcio y fósforo normales, Sudan III negativo, IGF-1 normal.

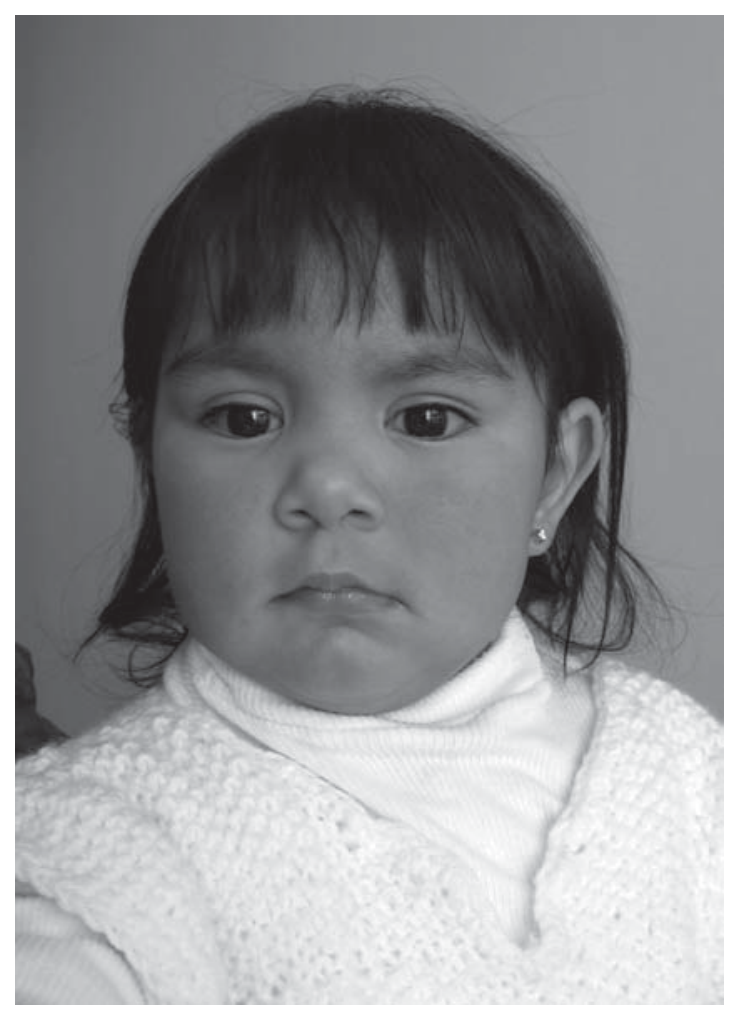

Figura 1. Paciente a los 18 meses de edad. Dismorfias faciales sutiles. 


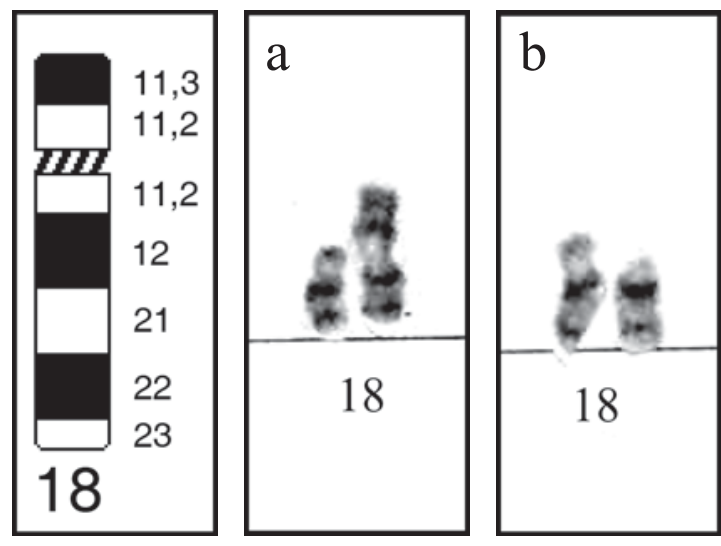

Figura 2. Idiograma cromosoma 18 y cariograma parcial de la paciente; a: i (18q) y b: del (18p).

Se solicitó evaluación por especialistas de nefrología, cardiología, genética, neurología y fonoaudiología.

Además se realizó estudio de imágenes: tomografía axial computada de cerebro normal, ecografía abdominal normal, ecocardiograma normal. Radiografía de carpo demostró discordancia del carpo, radiografía de columna lumbo sacra demostró hipoplasia cóccix, ecografía renal y vesical leve aumento ecogenicidad renal bilateral. DMSA normal, urodinamia normal, ecocardiograma normal y BERA normales.

El estudio cromosómico en sangre periférica mostró un mosaicismo cromosómico, cariotipo: 46,XX, i(18)(q10)[19]/46,XX,del(18)(p10) [12] (figura 2). El análisis cromosómico de ambos padres no mostró alteraciones numéricas ni estructurales.

Evoluciona con talla baja y leve retraso psicomotor con predominio del área de lenguaje expresivo. Actualmente, a la edad de 2 años y 10 meses, su peso 12060 gr y talla $85 \mathrm{~cm}$.

\section{Discusión}

La alteración estructural en mosaico que tiene nuestra paciente, es sumamente infrecuente. A priori podría pensarse que ella debiera tener signología tanto de la trisomía $18 \mathrm{q}$ como de deleción $18 \mathrm{p}$, situación que no se observa en ella.
En la trisomía $18 \mathrm{q}$ a diferencia de nuestro caso, se reporta retraso severo del desarrollo, cardiopatía congénita, fisura palatina y pie bot, lo cual compromete su sobrevida postnatal ${ }^{2,6}$. En cambio, el epicanto, puente nasal bajo, cuello corto y ancho, son rasgos observados en la deleción del brazo corto del cromosoma $18^{7,8}$. En algunos de ellos se observa malformaciones del SNC, con silla turca vacía ${ }^{9,10}$, lo que se descartó en esta niña.

El compromiso fenotípico y/o alteraciones en un individuo mosaico dependerán en gran medida de qué tejido y qué cuantía de ese tejido tenga tal o cual alteración. Nuestra paciente tiene dismorfias que se observan de preferencia en la deleción del brazo corto cromosoma 18. El retraso de lenguaje observado en ella es otra característica bien documentada de los portadores de esta deleción ${ }^{1,2,8}$.

La mayoría de las alteraciones cromosómicas en mosaico surgen en un cigoto que tiene ya una alteración cromosómica, sea ésta numérica o estructural. La ausencia de una línea celular con un cromosoma 18 normal, sugiere que al menos un rearreglo cromosómico se produjo antes de la concepción. La monosomía $18 \mathrm{p}$ ocurre por lo general como un evento "de novo" $(85 \%)^{8}$ y siendo más frecuente que el isocromosoma $18 \mathrm{q}$, postulamos que en este caso la deleción del brazo corto de un cromosoma 18 se produjo durante la gametogénesis probablemente paterna, ya que se reconoce que la mayor parte de los rearreglos estructurales cromosómicos se originan alli ${ }^{11}$, gestándose un cigoto 46, XX, del(18)(p10). Posteriormente, durante la duplicación mitótica del cromosoma 18 deletado, se debe haber producido una mala división centromérica, seguida de una no disyunción de este segmento quedando por tanto duplicado el brazo largo del cromosoma 18 (figura $3)$.

Los desbalances cromosómicos son dañinos debido a que algunos genes son dosis-sensible. En el caso de las duplicaciones existe un 150\% de la cuantía de un segmento cromosómico, mientras que en la deleción, hay un $50 \%$ de la cantidad normal. Una cantidad incorrecta de material cromosómico, dosis-sensible en cada célula de un embrión, va a distorsionar su desarrollo en mayor o menor grado. Dado que nues- 
tra paciente tiene un mosaicismo cromosómico en el que estamos postulando que la alteración inicial fuere la deleción $18 \mathrm{p}$, pudiese ser que estructuras críticas del desarrollo pudiesen haberse visto afectadas sólo por esta deleción que da un fenotipo más sutil, y que posteriormente apareciera la trisomía 18q en algunos tejidos o sistemas ya no tan críticos para el desarrollo de un individuo.

Una segunda hipótesis para explicar la escasez de signología en nuestra paciente, que tiene una línea celular con una trisomía parcial $18 \mathrm{q}$, podría ser que este segmento cromosómico estuviese sometido a imprinting. Si asumimos que la deleción 18p es de origen paterno, entonces el isocromosoma $18 \mathrm{q}$ también es paterno. Si este segmento cromosómico estuviese sometido a imprinting paterno y por tanto "silenciado", podría explicar que su presencia en triple dosis pudiese no ser tan deletérea ${ }^{11}$.

Dado que los padres tienen un cariotipo normal, la probabilidad de recurrencia es prácticamente nula, a excepción de que alguno de ellos tuviese una de estas alteraciones cromosómicas en mosaico a nivel gonadal, situación por lo demás muy infrecuente. Este poco probable mosaicismo gonadal se reconocería en la práctica sólo después que hubiere nacido otro niño/a con la misma alteración "de novo". Documentar mosaicismo gonadal en los padres resulta engorroso, ya que implicaría cariotipar gametos ${ }^{11}$.

Este caso ilustra la importancia de solicitar un cariograma en pacientes con talla baja, dismorfias y/o malformaciones, sin un diagnóstico etiológico establecido.

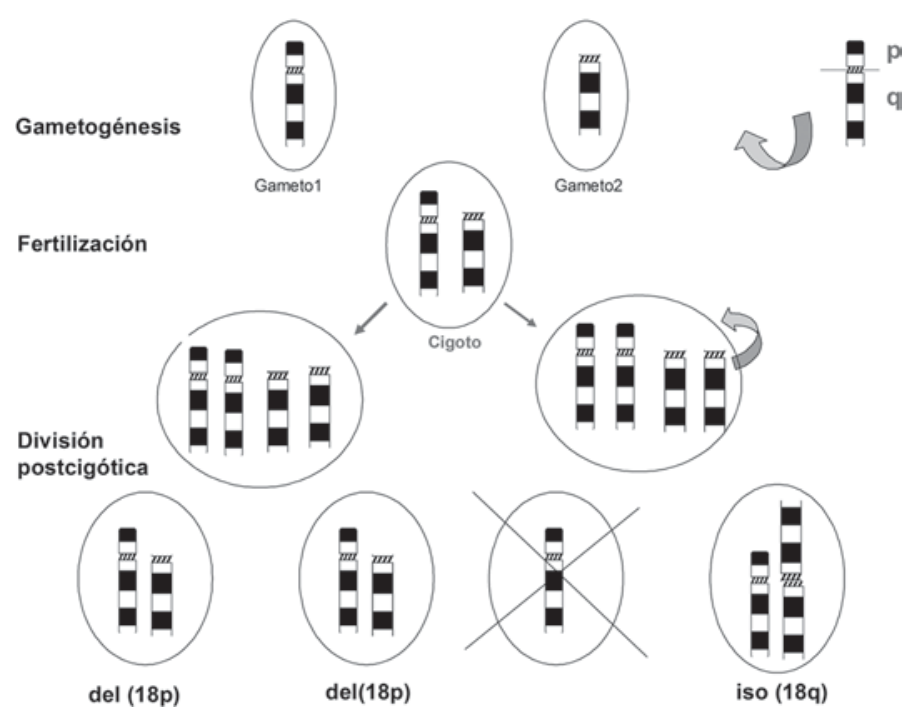

Figura 3. Generación de isocromosoma 18q en mosaico.

\section{Referencias}

1.- Sutton SD, Ridler MA: Prenatal detection of monosoy $18 \mathrm{p}$ and trisomy $18 \mathrm{q}$ mosaicism with unexpected fetal phenotype. J Med Genet 1986; 23 (3): 258-9.

2.- Turan S, Saka N, Guney I, Bereket A: A patient with hypopituitarism and isochromosome 18q mosaicism. Horm Res 2005; 64 (6): 261-5.

3.- Wurster-Hill DH, et al: Trisomy 18 and $18 \mathrm{p}$ - features in a case of isochromosome 18q [46,XY,i(18q)]: prenatal diagnosis and autopsy report. Clin Genet 1991; 39 (2): 142-8.

4.- Pal S, Siti MI, Ankathil R, Zilfalil BA: Two cases of isochromosoma 18q syndrome. Singapore Med J 2007; 48(5): e 146-50.

5.- Noe Souraty N, et al: Cytogenetic investigation of a child with a mosaic isochromsome 18q and ring 18q. Eur J Med Genet 2007; doi:10.1016/j.ejmg.2007. 06.001.

6.- Bass HN, Sparkes RS, Miller AA: Features of trisomy 18 and 18psyndromes in an infant with 45,XY,i(18q). Clin Genet 1979; 16: 163-8.

7.- de Grouchy J, Turleau C: Clinical Atlas of Human Chromosomes, $2^{\text {nd }}$ Ed. New York, John Wiley \& Sons, 1984.

8.- Laranjeria $C$ : Síndrome 18p familiar. Caso clínico. An Pediatr (Barc) 2009; 70: 89-90.

9.- Artamn HG, Morris C A, Stock AD: 18p- syndrome and hypopituitarism. J Med Genet 1992; 29: 671-2.

10.- Schober E, Scheibenreiter S, Frisch H: 18p monosomy with GHdeficiency and empty sella: good response to GH- treatment. Clin Genet 1995; 47: 254-6.

11.- Gardner RJ, Sutherland GR: Chromosomal abnormalities and Genetic counseling, Third edition, Oxford University Press 2004. 